\section{Organic Orchard Floor Management Systems for Apple Effect on Rootstock Performance in the Midwestern United States}

\author{
Dario Stefanelli ${ }^{1,2}$, Roberto J. Zoppolo, and Ronald L. Perry \\ Michigan State University, Department of Horticulture, East Lansing, \\ MI 48824
}

\author{
Franco Weibel \\ Research Institute for Organic Agriculture, (FiBL), Frick, Switzerland
}

Additional index words. 'Pacific Gala', Swiss sandwich system, propane flame burning, mulching, sustainable agriculture, M.9 NAKB 337, M.9 RN 29, Supporter 4

\begin{abstract}
In organic apple production systems, orchard floor management is of prime importance because it determines weed management and soil fertility. In this experiment, we evaluated the response of the cultivar Pacific Gala on three rootstocks of different vigor: M.9 NAKB 337, M.9 RN 29, and Supporter 4 (in respective order of vigor from dwarfing to semivigorous). The rootstocks were also evaluated for the response to three orchard floor management systems (OFMSs): mulching using alfalfa hay, flame burning, and shallow strip tillage using the Swiss sandwich system (SSS). The experiment was conducted in an experimental orchard planted in 2000.
\end{abstract}

Tree growth and nutrition were unaffected by orchard floor management system (OFMS) treatments except for foliar nitrogen concentration, which was higher with alfalfa mulch. Trees grafted on Supporter 4 were the most vigorous. There was a significant interaction between treatments and rootstocks with the highest yield and yield efficiency under the flame burning and Swiss sandwich system (SSS) treatments occurring with trees grafted on M.9 RN 29 rootstock. Cumulative yield was highest in the mulch and SSS treatments. No yield differences were evident between rootstocks under the mulch treatment despite overall improved tree appearance. The flame-burning treatment increased the risk of fire, branch injury, and damage to plastic irrigation systems despite having relatively low costs under experimental orchard conditions. Drawbacks to the alfalfa hay mulch treatment included the expense, maintenance and risk of rodent damage, potential for nutrient leaching, and selection toward perennial weed species. The SSS provided less suitable growing conditions with lower soil organic matter (SOM), foliar nitrogen levels, and soil moisture in the vegetated area despite ease of installation and management

\footnotetext{
Received for publication 8 Aug. 2008. Accepted for publication 3 Dec. 2008.

We thank the personnel at Clarksville Horticultural Experiment Station for the help in data collection and orchard maintenance.

${ }^{1}$ Current address: Department of Primary Industries, Knoxfield Centre, Future Farming Systems Research Division, 621 Burwood Highway, Knoxfield Victoria 3180, Australia.

${ }^{2}$ To whom reprint requests should be addressed; e-mail dario.stefanelli@dpi.vic.gov.au.
}

with a modified notch disk tiller and low expense. The results may suggest that the M.9 RN 29 rootstock adapts well to stress conditions presented by the SSS and flameburning treatments.

Organic horticulture is becoming one of the fastest growing sectors in agriculture economy (Dimitri and Greene, U.S. Department of Agriculture, 2002; Organic Trade Association, 2005) because of a worldwide growing interest in the development of sustainable food production systems (Delate et al., 2008a; Yussefi, 2004). In organic agriculture, inputs are limited to those approved by recognized certification agencies. Challenges include management of soil fertility and insect pests, diseases, and weeds (Delate et al., 2008b).

There is a need, therefore, to identify management systems that are productive under these constraints (Delate et al., 2008a). In tree fruit production, OFMSs are intended to create the best environment for tree growth, allowing for maximum tree performance (Weibel, 2002). A successful OFMS in organic systems should increase soil fertility and improve soil physical and biological properties and tree nutrition while suppressing weeds without the use of conventional herbicides and minimize insect pest and disease pressure.

Several OFMSs have been adopted by commercial fruit growers to satisfy practical needs such as mulching with organic or inorganic material. Mulch assists in keeping the soil free from vegetation, conserves soil moisture, keeps temperature constant, increases organic matter through decomposition, releases nutrients to the soil, and improves the soil environment by enhancing microbial activity (Lloyd et al., 2002; Marsh et al., 1996; Merwin et al., 1994, 1995; Sanchez et al., 2003; Yao et al., 2005). However, mulching has some drawbacks such as disease (Merwin et al., 1994), increased rodent population (Merwin and Ray, 1999), nutrient competition, and attraction of pests (Granatstein and Mullinix, 2008). Tillage is still widely used in OFMS as a weed suppressor but can impede internal water drainage, cause surface organic matter losses (Merwin et al., 1994), and disrupt surface roots (Cockroft and Wallbrink, 1996). Recently, a modified tillage system has been developed in Switzerland called the SSS. It consists of a strip where spontaneous vegetation is allowed to grow in the tree row with two shallow tilled strips at each side of the tree row. The SSS encourages predatory insects to complete their life cycle in volunteer vegetation that grows in the tree row, thus limiting pests and diseases and increasing biodiversity (Gaolach, 2000; Horton, 1999; Luna and Jepson, 1998; Schmid and Weibel, 2000). The resulting vegetation in the tree row can be considered as cover crops, contributing significantly to the system by improving soil conditions and enhancing nutrient cycling (Marsh et al., 1996; Miles and Chen, 2001; Stork and Jerie, 2003; Yao et al., 2005). The SSS is easy to manage because there is no need to mow weeds or till under the tree canopy, avoiding potential damage to the trunk as well as roots, especially for young trees (Schmid and Weibel, 2000; Weibel, 2002; Weibel and Häseli, 2003). The two strips of shallow tilled soil have the added effect of reducing vegetation competition for water and nutrients (Merwin and Ray, 1997). Propane flame burning is another OFMS practice in regular use by organic growers (Gourd, 2002; Robinson, 2003) with relatively little known regarding beneficial effects besides vegetation suppression. Drawbacks include increased fire risk, damage to trees (Zoppolo, 2004), and the need for specialized application equipment. These OFMS have been reported to successfully keep soil surfaces free of competitive vegetation that would negatively impact tree growth (Merwin and Ray, 1997; Parker, 1990; Welker and Glenn, 1991).

Another form of orchard management that growers can use is the selection of appropriate rootstocks. There is a wide variety of specifically selected apple rootstocks that have been developed and released over many years. Each rootstock differs in adaptation to soil conditions (Ferree and Carlson, 1987; Marini et al., 2000), disease resistance, and influence of the vigor and productivity of the scion. Rootstock evaluation is usually performed using conventional practices under optimal growing conditions. Environmental factors have been reported to influence the uptake of nitrogen and phosphorus more than the rootstock genotype (Kennedy et al., 1980). There is a strong relationship between genetic (vigor) and environmental factors in determining the adaptability of the root system and capacity for nutrient uptake 
and tree performance under adverse conditions (Ferree and Carlson, 1987).

Because organic OFMS create environmental conditions that are different from the conventional practices in which rootstocks are evaluated, our hypothesis was that rootstock choice may compensate and overcome these differences. The objectives of this work were to evaluate the responses of selected rootstocks to different growing conditions present in the OFMSs (mulch, propane flame burning, and the SSS) and to determine the suitability for growers interested in alternative OFMSs under an organic protocol.

\section{Materials and Methods}

An experimental orchard of 'Pacific Gala' apple trees (Malus $\times$ domestica Borkh.) was planted in Apr. 2000 at the Clarksville Horticulture Research Station in Clarksville, MI. The predominant soil type of the orchard and the surrounding areas is Kalamazoo sandy clay loam (Typic Hapludalfs) with $53.1 \%$ sand, $23.1 \%$ silt, and $23.8 \%$ clay. The orchard is situated on mild slopes (less than $3 \%$ ). The site was previously farmed with a conventional soybean-maize-maizealfalfa rotation for two cycles until 1998. Subsequent soil preparation consisted of sowing of buckwheat (Fagopyrum esculentum, L.) and chicken manure compost (1250 $\left.\mathrm{kg} \cdot \mathrm{ha}^{-1}\right)$ and lime $\left(2250 \mathrm{~kg} \cdot \mathrm{ha}^{-1}\right)$ application in 1999 on the entire soil surface. At planting (Apr. 2000), a mixture of mammoth red clover (Trifolium pratense var. perenne L.) and endophytic rye grass (Lollium perenne, L. infected with Neotyphodium lolii, L.) was sown in the alleys (Table 1). The orchard was certified organic in 2003 and 2004 by the Organic Crop Improvement Association and in 2005 by Organic Growers of Michigan. Data collection for this study was initiated in 2002 and ended in 2005.

The rootstocks under evaluation were the dwarfing M.9 NAKB 337 (40\% of the size of a normal seedling; Marini et al., 2000), the semidwarfing M.9 RN 29 (Perry, 2000a), and the semivigorous Supporter 4 (Perry, 2000b). Spacing between the trees was dependent on rootstock vigor (Perry, 2002) and was $4.6 \times 1.4 \mathrm{~m}$ for M.9 NAKB 337 (1553 tree/ ha), $4.6 \times 1.7 \mathrm{~m}$ for M.9 RN 29 (1279 tree/ha), and $4.6 \times 2.0 \mathrm{~m}$ for Supporter 4 (1087 tree/ha).

Trees were trained to a vertical axis system. Rubber bands and clothes pins were used to bend branches in establishment years (Perry, 2000c). Minimal pruning was applied to allow the tree to grow as naturally as possible to create a leader or main branches (Perry, 2000c). A two-wire trellis with galvanized metal poles was installed as a support system. Drip irrigation capable of emitting $2.3 \mathrm{~L} \cdot \mathrm{h}^{-1}$ every $0.6 \mathrm{~m}$ was installed in May 2001 and suspended from the lowest wire of the trellis on the tree row. All OFMSs received equal irrigation time and frequency throughout the seasons.

The OFMS treatments were applied in 2001 (Table 1) and consisted of mulch, SSS, and flaming with a propane burner. The

Table 1. Timetable summary on the history of the site and treatments, sampling, and measurements for the duration of the experiment.

\begin{tabular}{ll}
\hline Time period & \multicolumn{1}{c}{ Soil management, cultural practice/measurement collected } \\
\hline 1998 & Conventional soybean-maize-maize-alfalfa rotation (two cycles); \\
& last crop was corn; minimal tillage \\
& Spring: tillage, sowing of soybean, chicken compost $\left(1250 \mathrm{~kg} \cdot \mathrm{ha}^{-1}\right)$, \\
& lime $\left(2250 \mathrm{~kg} \cdot \mathrm{ha}^{-1}\right) ;$ fall: tillage, sowing of buckwheat \\
2000 & April: tillage, tree planting; August: sowing of mammoth red \\
& clover and endophytic rye grass in the alleys/TCA \\
2001 & May: implementation of the three orchard floor management systems/TCA, \\
& TCAI, shoot growth, canopy volume, leaf nitrogen content, SPAD, soil sampling, \\
& and soil moisture \\
Maintenance of the OFMSs and tree training/TCA, TCAI, shoot growth, canopy volume, \\
leaf nitrogen content, SPAD, soil sampling, soil moisture, and yield from 2003
\end{tabular}

OFMSs $=$ orchard floor management systems; TCA $=$ trunk cross-sectional area; TCAI $=$ trunk crosssectional area increase.

primary objective of the treatments was weed management. The mulch treatment consisted of alfalfa hay with a carbon:nitrogen ratio of 15:1 applied underneath the tree canopy in a strip $1 \mathrm{~m}$ on each side of the tree at a minimum thickness of 15 to $20 \mathrm{~cm}$. The mulch treatment required 115 round alfalfa bales/ha/year. Nitrogen delivered with each mulch application was estimated to be 550 $\mathrm{kg} \cdot \mathrm{ha}^{-1}$. Mulch was hand-applied every spring and fall to maintain a constant thickness for weed suppression and maintenance of soil moisture. No supplementary weed control was applied. The flame-burning treatment consisted of heating weeds underneath the tree canopy and $1 \mathrm{~m}$ each side of the tree using flames generated from burning propane gas (estimated $56 \mathrm{~L} \cdot \mathrm{ha}^{-1} /$ year). A customengineered burner, consisting of four burners $(200,000$ BTU each) in a row, with a metal protective shield to concentrate the heat and to prevent flame damage to the tree canopy was used. A sprinkler system was mounted on the back of the shield to extinguish fires occurring during treatment application. The burner was mounted on the side of a tractor on a hydraulic arm. To reach the weeds underneath the canopy on the tree row, a hand burner (150,000 BTU) was used. The treatment was applied five to six times during the year, starting in late April/early May and ending in late August. The treatment was repeated whenever weeds reached $10 \mathrm{~cm}$ high. Tractor speed was kept between 1.6 and $3.2 \mathrm{~km} \cdot \mathrm{h}^{-1}$ depending on the density of the weeds to be controlled. No additional fertilization was applied. The SSS we used was an adaptation of the system developed in Switzerland (Weibel, 2002) and was applied to an area 25 to $30 \mathrm{~cm}$ on each side of the tree, underneath the canopy, where vegetation was allowed to grow undisturbed. On each side of this weedy area, two strips of soil were kept free of vegetation by shallow tillage ( 5 to 10 $\mathrm{cm}$ deep). The strips were $70 \mathrm{~cm}$ wide from 2001 to 2003 and $90 \mathrm{~cm}$ wide from 2004 onward. The width of the strip was modified to follow tree growth. Timing and frequency of the treatment application was the same as the flame-burning treatment. Tillage was applied by a three-tooth arrow tiller sidemounted on a tractor on a hydraulic arm through 2003, a five-tooth arrow tiller in 2004, and a modified notch disk tiller in
2005. The notch disk tiller was modified to reach the side of the tractor (Fig. 1A-B). No additional fertilization was applied.

The alley consisted of an equal mixture of endophytic rye grass and mammoth red clover seeded at orchard planting. Clover was reseeded in 2005 to keep the stand proportion constant. Alleys were not irrigated and managed equally for all treatments by periodically mowing (three to four times per year) and cuttings were left in place according to best management farming practices.

Soil moisture was measured in each OFMS by time domain reflectometry (TDR) using a Mini Trase 6050X3 (Soilmoisture Equipment Corp., Goleta, CA) with 45-cm long stainless steel rods permanently installed in the tree rows halfway between two trees and in the middle of the tilled strip in 2002. Measurements were taken weekly in 2002 and every other week from 2003 onward. All expenses, including labor and equipment use, were recorded in 2005 to roughly quantify OFMS maintenance costs.

Tree growth variables. We measured trunk cross-sectional area (TCA), $25 \mathrm{~cm}$ above graft union, at dormancy, as well as its differential increase (TCAI) since establishment, for all years. This methodology has been shown to be highly correlated with tree growth and vigor in young trees (Westwood and Roberts, 1970). Shoot growth (extension) was measured weekly on three representative shoots per tree and the tree leader during all vegetative seasons to measure tree growth

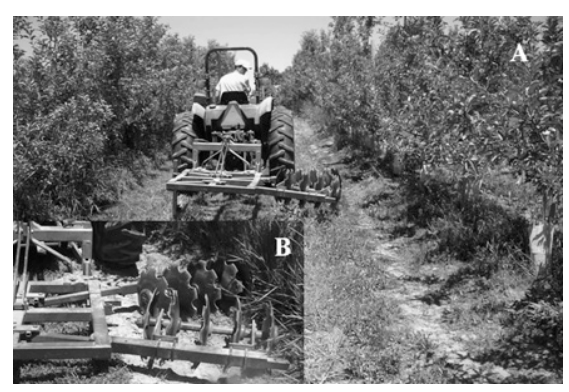

Fig. 1. (A) Modified notch disk tiller for the implementation and maintenance of the Swiss sandwich system (SSS) tilled strip. (B) Modification in the disk setup for the notch disk tiller. 
rate. Shoots were selected to represent the bottom, middle, and top part of the tree. Selected shoots were comparable in size and branch insertion angle at the time of selection. Canopy volume was calculated measuring the total height as well as two orthogonal diameters of the canopy at $0.7 \mathrm{~m}$ from the soil surface.

Production variables. Yield ( $\mathrm{kg} /$ tree) and fruit number as well as cumulative yield across all years was assessed. Values were corrected to the actual number of trees to obtain production/ha. Yield efficiency, or ratio of fruit yield to trunk area, was calculated by dividing the annual yield of the current year by TCA of the previous year. Cumulative yield efficiency was calculated by dividing the cumulative yield by the TCAI of the current year.

Tree nutritional status. Relative chlorophyll content of a composite sample of 10 leaves per data tree was collected from the middle portion of 1-year-old shoots using a SPAD-502 m (Spectrum Technologies Inc., Plainfield, IL) in early August each year. Total mineral nitrogen concentration of the previously described composite sample of leaves was determined by the following method. Leaves were rinsed with distilled water, airdried at $60^{\circ} \mathrm{C}$ for $48 \mathrm{~h}$, ground, and sent to the Michigan State University soil and plant nutrition laboratory and analyzed for total nitrogen content using the Kjeldahl method.

Treatments were applied in a completely randomized split-plot design with OFMS as main plots and rootstocks as subplots with six replicates. Four trees for each rootstock were planted in each subplot. Two central trees for each rootstock were used as data trees for a total of 108 trees under evaluation. Statistical analysis was performed using SAS software (Version 8; SAS Institute, Cary, NC). Analysis of variance was performed using the MIXED procedure to detect treatment effects. When significant, mean separation was conducted by least square means test with $P \leq$ 0.05 . The soil moisture data were analyzed as repeated measures using OMFS $\times$ rootstock as the factors.

\section{Results}

In 2005 , for all growth variables considered, there was no significant OFMS treatment effect and no interaction between the treatments and rootstocks (Fig. 2; Table 2). Only during the establishment and training years (2001 to 2003) did the OFMS treatments affect branch growth, TCA, and TCAI with the highest values under the mulch treatment (data not shown). However, once the trees reached full production (2004), the treatment effect ceased to be significant (data not shown).

Among rootstocks, trees on Supporter 4 had the highest values in most growth variables considered (Fig. 2) with no significant differences between the other two rootstocks (M.9 RN 29 and M.9 NAKB 337). Branch growth in 2005 ranged between $38 \mathrm{~cm}$ for M.9 RN 29 in the mulch treatment and $43 \mathrm{~cm}$

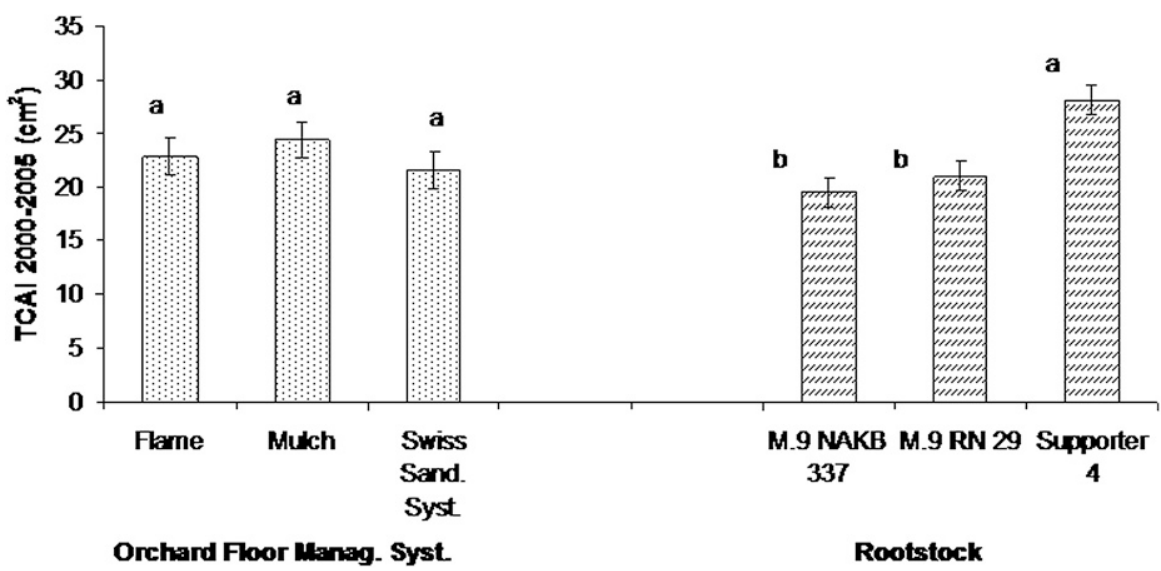

Fig. 2. Trunk cross-sectional area increase (TCAI) from 2000 to 2005 for orchard floor management systems (flame burning, mulch, and Swiss sandwich system) and rootstocks (M.9 NAKB 337, M.9 RN 29, and Supporter 4). Mean separation was performed using least square means at $P \leq 0.05$. Bars represent SE.

Table 2. Summary of analysis of variance $(P>\mathrm{F})$ indicating significant source effects on tree growth variables measured during 2005 .

\begin{tabular}{lrccc}
\hline Source & TCA & TCAI & Canopy volume & Branch extension \\
\hline OFMS & 0.5273 & 0.9780 & 0.5305 & 0.7672 \\
Rootstock & $<0.0001$ & 0.0010 & $<0.0001$ & 0.4368 \\
OFMS $\times$ rootstock & 0.4069 & 0.3494 & 0.4069 & 0.6592 \\
\hline
\end{tabular}

OFMS $=$ orchard floor management system; TCA $=$ trunk cross-sectional area; TCAI $=$ trunk crosssectional area increase 2000 to 2005 .

for M.9 NAKB 337 and Supporter 4 in the SSS treatment.

Rootstock did not influence the nitrogen status of the leaves (data not shown). Beginning in 2003, the mulch treatment showed higher leaf nitrogen concentration than the SSS and flame-burning treatments (Table 3). Once the trees reached full production (2004), leaf nitrogen concentration declined in all treatments (Table 3).

Crop load (kg/tree) was not influenced by OFMS, but significant differences were evident among rootstocks and an interaction occurred between rootstocks and OFMSs (Table 4). Rootstock did not impact on crop levels in mulch-treated trees. The rootstock M.9 RN 29 was the most productive with no differences between the other two rootstocks under SSS and flame-burning treatments (Fig. 3). Yield efficiency had the same trend as yield with M.9 RN 29 presenting higher values in the trees under SSS and flameburning treatments, whereas no significant differences were measured between rootstocks under the mulch treatment (Fig. 3).

When values were corrected by the number of trees per hectare, there was no influence of the OFMS on any of the production variables, but there was a significant rootstocktreatment interaction (Table 4). Yield and yield efficiency had the same trend as cumulative yield in which there was no difference among the rootstocks in the flame-burning treatment (Fig. 4). Supporter 4 had the lowest production under the mulch and SSS treatments, whereas M.9 NAKB 337 had the highest cumulative yield under the mulch treatment and M.9 RN 29 in the SSS treatment (Fig. 4).
Measurements performed with TDR demonstrated that 10 to 11 of 12 to 13 times per year, there were no differences among OFMSs varying between $15 \%$ and $25 \%$ in volumetric content (data not shown). When differences were observed (once or twice per year), the soil under the mulch treatment always had the highest soil moisture content, whereas the soils in the vegetated area in the SSS treatment had the lowest moisture content. Soil moisture in the flame burning and tilled strip in the SSS treatment did not differ from the other two sites (data not shown).

\section{Discussion and Conclusions}

The mulch treatment created the most favorable soil conditions for 'Pacific Gala' tree growth having higher concentrations of SOM, nitrogen $(\mathrm{N})$, and moisture in the soil, whereas the other two treatments had similar soil conditions (Stefanelli, 2006; Zoppolo, 2004). This was reflected in the higher foliar $\mathrm{N}$ concentration, as has been reported by Nielsen and Hogue (1985) and Merwin and Stiles (1994). Optimal leaf $\mathrm{N}$ concentrations have

Table 3. Total nitrogen content (percent dry weight) in apple leaves from 2001 to 2005.

\begin{tabular}{lccccc}
\hline OFMS & 2001 & 2002 & 2003 & 2004 & 2005 \\
\hline Mulch & 2.1 & $2.4 \mathrm{a}^{\mathrm{z}}$ & $2.7 \mathrm{a}$ & $2.2 \mathrm{a}$ & $2.1 \mathrm{a}$ \\
Sandwich & 2.1 & $2.2 \mathrm{~b}$ & $2.2 \mathrm{c}$ & $1.8 \mathrm{~b}$ & $1.8 \mathrm{~b}$
\end{tabular}

\begin{tabular}{llllll} 
Sandwich & 2.1 & $2.2 \mathrm{~b}$ & $2.2 \mathrm{c}$ & $1.8 \mathrm{~b}$ & $1.8 \mathrm{~b}$ \\
Flame & 2.1 & $2.4 \mathrm{a}$ & $2.4 \mathrm{~b}$ & $1.9 \mathrm{~b}$ & $1.8 \mathrm{~b}$ \\
\hline
\end{tabular}

${ }^{\mathrm{z}}$ Mean separation within columns by least square means test adjusted with Tukey. Different letters represent statistical difference $(P \leq 0.05)$. No letters indicates absence of statistical significance. OFMS $=$ orchard floor management system. 


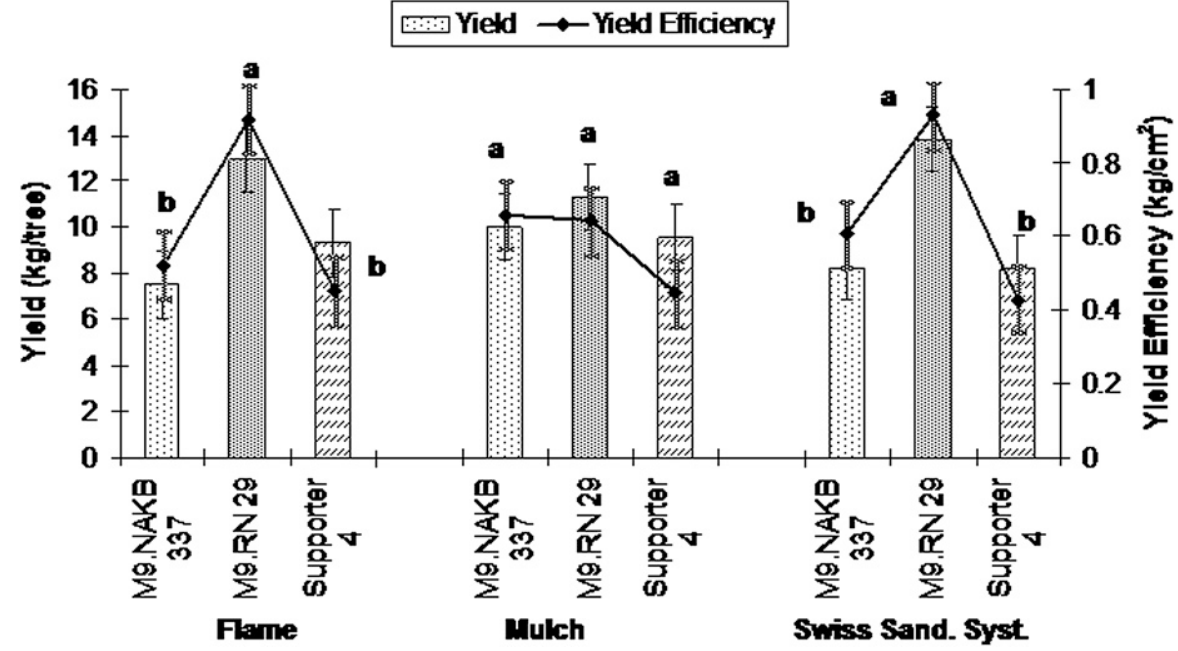

Fig. 3. Rootstock (M.9 NAKB 337, M.9 RN 29, and Supporter 4) productivity (kg/tree), expressed by the columns, and yield efficiency $\left(\mathrm{kg} \cdot \mathrm{cm}^{-2}\right)$, expressed by the line, in 2005 for each rootstock separated by orchard floor management system (OFMS; flame, mulch, and Swiss sandwich system). Means separation within each OFMS was performed using least square means at $P \leq 0.05$. Letters apply to both yield and yield efficiency. Thin histogram bars represent sE for rootstock's yield. Thick line bars represent SE for rootstock's yield efficiency.

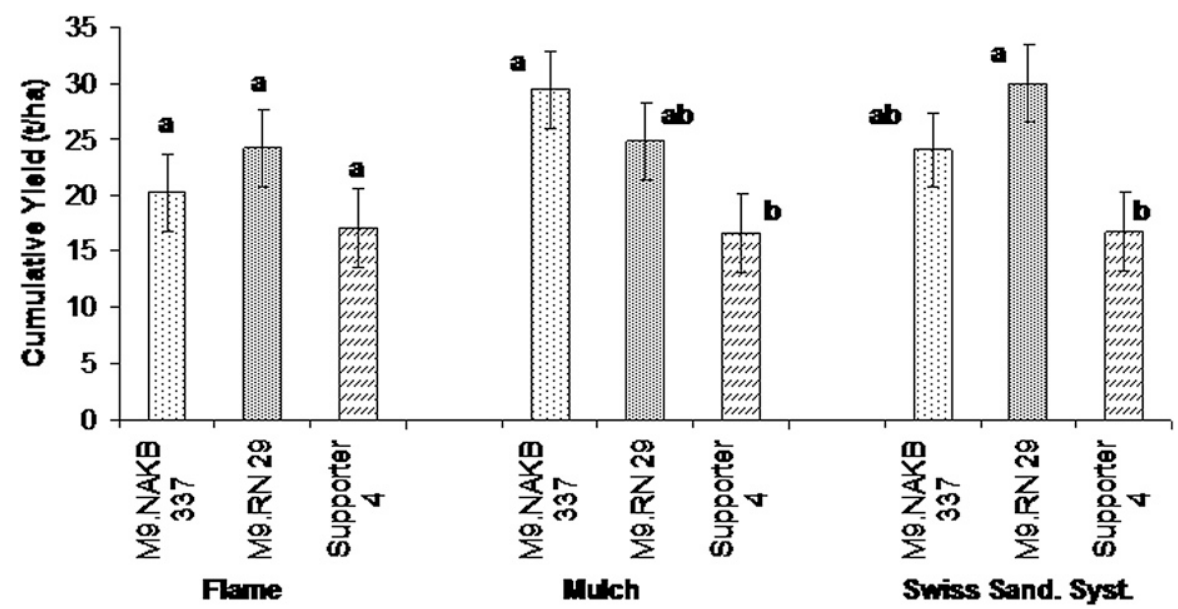

Fig. 4. Cumulative yield from 2003 to 2005 for each rootstock (M.9 NAKB 337, M.9 RN 29, and Supporter 4), separated by orchard floor management system (OFMS; flame burning, mulch, and Swiss sandwich system). Mean separation within OFMSs was performed using least square means at $P \leq 0.05$. Bars represent SE of treatment means.

not been determined for all cultivars, but leaf $\mathrm{N}$ values in this study were approaching the lowest acceptable range for Michigan apple orchards (Hanson, 1996; Hanson and Hull, 1986), especially once trees reached full production (2004), suggesting that fertilization may be appropriate in the future. Additional OFMS fertilization studies should be performed. Trees in this study, however, exhibited acceptable levels of branch growth, TCA, TCAI, and canopy volume (Hanson, 1996).
Drawbacks to the alfalfa hay mulch treatment in this study included the expense, maintenance, and risk of rodent damage and potential for nutrient leaching. Mulch was also ineffective in controlling quackgrass (Agropyron repens L.) becoming, thus, unsuitable in areas where this weed is common. The flame-burning treatment, although very effective in weed suppression, presented risks of fire, branch injury, and damage to plastic irrigation systems despite having rel- atively low costs under experimental orchard conditions. The SSS provided less suitable growing conditions, with lower SOM, foliar $\mathrm{N}$ levels, and soil moisture in the vegetated area, despite ease of installation and management with a modified notch disk tiller (Fig. $1 \mathrm{~A}-\mathrm{B}$ ) and lowest expense.

Despite the effect of the OFMS treatments on soil conditions, minimal effect on growth variables (TCA, TCAI, branch growth, and canopy volume) was measured. During initial years of the orchard (2001 to 2003), however, the SSS treatment had the least growth (Zoppolo, 2004), probably as a result of competition exerted by the vegetated area under the canopy (Giovannini et al., 1998; Merwin and Ray, 1997; Parker 1990; Welker and Glenn, 1991). An expansion of the width of the tilled strip in 2004 may have reduced competition with weeds and resulted in increased growth. Trees on Supporter 4 were more vigorous than the M.9 clones used in the experiment as noted in previous studies (Marini et al., 2000). The lack of OFMS effect on tree vigor could be explained by the lower carbon:nitrogen ratio measured in pruning wood, leaves, and fruit in trees under the mulch treatment in 2004 (data not shown).

Although there was no effect of OFMS on tree vigor, there was an interaction between treatments and rootstocks regarding crop load. In the mulch treatment, there were no measurable differences among the rootstocks, whereas in both the flame-burning and SSS treatments, M.9 RN 29 had the highest yield and yield efficiency with no differences between the other two rootstocks (Fig. 3). It is well known that trees on dwarfing rootstocks bear fruit earlier than vigorous rootstocks (Webster, 2000). M.9 RN 29 appears to be a rootstock that adapts better to the less favorable growing conditions presented by the SSS and propane flame-burning treatments (lower SOM, N, and water content in the vegetated area of the sandwich) (Stefanelli, 2006; Zoppolo, 2004) as expressed by the higher yield efficiency measured in these two treatments as compared with the mulch treatment. M.9 RN 29's better performance in the SSS and flame-burning treatments could be attributed to higher $\mathrm{N}$ use efficiency as suggested from the increased carbon:nitrogen ratios shown in 2004 (data not shown). In the limited testing performed in 2004, M.9 RN 29 had higher fruit, leaves, and pruning wood carbon:nitrogen ratios in the SSS and flame-burning treatments than in the mulch treatment. Further investigation on rootstock nutrient and water use efficiency under organic protocols should be performed. In any case, the three

Table 4. Summary of analysis of variance $\left(P>\right.$ F) indicating significant source effects on production variables measured during $2005 .^{\mathrm{z}}$

\begin{tabular}{|c|c|c|c|c|c|c|c|}
\hline Source & $\begin{array}{l}\text { Avg fruit } \\
\text { wt (g) }\end{array}$ & Yield (kg/tree) & $\begin{array}{c}\text { Cumulative yield } \\
(\mathrm{kg} / \text { tree })\end{array}$ & $\begin{array}{l}\text { Yield efficiency } \\
\quad\left(\mathrm{kg} \cdot \mathrm{cm}^{-2}\right)\end{array}$ & $\begin{array}{l}\text { Cumulative yield } \\
\text { efficiency }\left(\mathrm{kg} \cdot \mathrm{cm}^{-2}\right)\end{array}$ & Yield (t.ha- $\left.{ }^{-1}\right)$ & $\begin{array}{c}\text { Cumulative yield } \\
\left(\mathrm{t} \cdot \mathrm{ha}^{-1}\right)\end{array}$ \\
\hline OFMS & 0.0652 & 0.9688 & 0.6813 & 0.7572 & 0.4304 & 0.9370 & 0.6014 \\
\hline Rootstock & 0.1078 & 0.0001 & 0.0007 & $<0.0001$ & $<0.0001$ & $<0.0001$ & $<0.0001$ \\
\hline OFMS $\times$ rootstock & 0.4360 & 0.0304 & 0.0454 & 0.0474 & 0.0414 & 0.0303 & 0.0414 \\
\hline
\end{tabular}

${ }^{\mathrm{z}}$ Cumulative values represent data collected from 2003 to 2005.

OFMS = orchard floor management system. 
rootstocks exhibited comparable production with conventional rootstock trials (NC.140) performed in the same research station (data not published). When values were corrected by tree density, the lowest cumulative yield per hectare occurred with the flame-burning treatment, whereas no differences were observed between rootstocks (Fig. 4).

Yield and yield efficiency per tree as well as the cumulative production per hectare, even if somewhat diminished by the reduced number of trees per hectare, suggest that M.9 RN 29 and the low-cost SSS are the most suitable combination that should be considered by growers who want to plant 'Pacific Gala' under organic protocols in Michigan and related climatic regions. More research is needed to address the applicability of the SSS in the midwestern regions, considering that weed populations in organic orchards can be very aggressive and competitive.

\section{Literature Cited}

Cockroft, B. and J.C. Wallbrink. 1996. Root distribution of orchard trees. Aust. J. Agr. Res. 17:49-54.

Delate, K., A. McKern, R. Turnbull, J.T.S. Walker, R. Volz, A. White, V. Bus, D. Rogers, L. Cole, N. How, S. Guernsey, and J. Johnston. 2008a. Organic apple systems: Constraints and opportunities for producers in local and global markets: Introduction to the colloquium. HortScience 43:6-11.

Delate, K., A. McKern, R. Turnbull, J.T.S. Walker, R. Volz, A. White, V. Bus, D. Rogers, L. Cole, N. How, S. Guernsey, and J. Johnston. 2008b. Organic apple production in two humid regions: Comparing progress in pest management strategies in Iowa and New Zealand. HortScience 43:12-21.

Dimitri, C. and C. Greene, U.S. Department of Agriculture. 2002. Recent growth patterns in the U.S. Organic Foods Market. U.S. Dept. Agr., Washington, DC. Economic Research Service: 42.

Ferree, D.C. and R.F. Carlson. 1987. Apple rootstocks, p. 107-143. In: Rom, R.C. and R.F. Carlson (eds.). Rootstocks for fruit production. John Wiley \& Sons, Inc., New York, NY.

Gaolach, B. 2000. Impacts of undersowing clover and arugula on insect abundance in broccoli (Brassica olearcea). Organic Farming Research Foundation. Funded projects. Managing insect pests. 23 June 2008. <http://ofrf.org/funded/ reports/gaolach_00-17.pdf>.

Giovannini, D., D. Scudellari, A. Aldini, G. Ceredi, and B. Marangoni. 1998. Risultati di un triennio di ricerche sulla gestione del terreno di un pescheto biologico. Atti IV giornate scientifiche S.O.I.', 1-3 Aprile 1998:181-182.

Gourd, T. 2002. Controlling weeds using propane generated flame and steam treatments in crop and non-croplands. Organic Farming Research Foundation. Funded projects. Weed management. 23 June 2008. <http://ofrf.org/funded/reports/ gourd_02s06.pdf>.

Granatstein, D. and K. Mullinix. 2008. Mulching options for Northwest organic and conventional orchards. HortScience 43:45-50.

Hanson, E.J. 1996. Fertilizing fruit crops. Mich. State Univ. Coop. Ext. Service Bul. 852.

Hanson, E.J. and J. Hull. 1986. Plant tissue analysis for determining fertilizer needs of Michigan fruit crops. Mich. State Univ. Coop. Ext. Service Bul. 449.
Horton, D. 1999. Enhancing biological control in mating disruption and organic pear orchard by understorey management. Organic Farming Research Foundation. Funded projects. Managing insect pests. 23 June 2008. <http://ofrf.org/ funded/reports/horton_98-06.pdf $>$.

Kennedy, A.J., R.W. Rowe, and T.J. Samuelson. 1980. The effects of apple rootstock genotypes on mineral content of scion leaves. Euphytica 29:477-482.

Lloyd, J.E., D.A. Herms, B.R. Stinner, and H.A.J. Hoitink. 2002. Comparing composted yard trimmings and ground wood as mulches. Biocycle September:52-56.

Luna, J. and J. Jepson. 1998. Enhancement of biological control with beneficial insectary plantings. Organic Farming Research Foundation. Funded projects. Managing insect pests. 23 June 2008. <http://ofrf.org/funded/reports/ luna_98-27.pdf $>$.

Marini, R.P., J.L. Anderson, B.H. Barrit, G.R. Brown, J. Cline, W.P. Cowgill, Jr., P.A. Domoto, D.C. Ferree, J. Garner, G.M. Green, C. Hampson, P. Hirst, M.M. Kushad, E. Mielke, C.A. Mullins, M. Parker, R.L. Perry, J.P. Prive, T. Robinson, C.R. Rom, T. Roper, J.R. Schupp, E. Stover, and R. Unrath. 2000. Performance of 'Gala' apple on 18 dwarf rootstocks: A five year summary of the 1994 NC-140 semi-dwarf rootstock trial. J. Amer. Pomol. Soc. 54:92-107.

Marsh, K.B., M.J. Daly, and T.P. McCarthy. 1996 The effect of understorey management on soil fertility, tree nutrition, fruit production and apple fruit quality. Biol. Agr. Hort. 13:161173.

Merwin, I.A. and J.A. Ray. 1997. Spatial and temporal factor in weed interference with newly planted apple trees. HortScience 32:633-637.

Merwin, I.A. and J.A. Ray. 1999. Orchard groundcover management systems affect meadow vole populations and damage to apple trees. HortScience 34:271-274.

Merwin, I.A., D.A. Rosenberger, C.A. Engle, D.L. Rist, and M. Fargione. 1995. Comparing mulches, herbicides, and cultivation as orchard groundcover management systems. HortTechnology 5:151-158.

Merwin, I.A. and W.C. Stiles. 1994. Orchard ground cover management impacts on apple tree growth and yield, and nutrient availability and uptake. J. Amer. Soc. Hort. Sci. 119:209215.

Merwin, I.A., W.C. Stiles, and H.M. van Es. 1994. Orchard groundcover management impacts on soil physical properties. J. Amer. Soc. Hort. Sci. 119:216-222.

Miles, C. and C. Chen. 2001. Cover crops for weed management in organic farm. Organic Farming Research Foundation. Funded projects. Weed management. 23 June 2008. <http://ofrf.org/ funded/reports/miles_00-06.pdf>.

Nielsen, G.H. and E.J. Hogue. 1985. Effect of orchard soil management on the growth and leaf nutrient concentration of young dwarf red delicious apple trees. Can. J. Plant Sci. 65:309315.

Organic Trade Association. 2005. O.T.A. newsletter. Organic Trade Association, Greenfield, MA.

Parker, M.L. 1990. The response of fruit trees to orchard soil management. PhD Diss., Mich. State Univ. Dept. of Hort., East Lansing, MI. Abstr. 136.

Perry, R.L. 2002. Spacing the fruit. Mich. State Univ. Dept. of Hort. 20 June 2007. <http://www. hrt.msu.edu/department/Perry/Spacing_Fruit/ Spacing_Fruit_Index.htm>.
Perry, R.L. 2000a. Belgium produces more than waffles and chocolates. Fruit Crop Advisory Team. Fruit Ed. Mich. State Univ. Ext. 15: $1-2$.

Perry, R.L. 2000b. Brief comments about new apple stocks. Fruit Crop Advisory Team. Fruit Ed. Mich. State Univ. Ext. 15:5-7.

Perry, R.L. 2000c. Keys to maintaining productive vertical axe trees. Fruit Crop Advisory Team. Fruit Ed. Mich. State Univ. Ext. 15:2-3.

Robinson, T. 2003. Insect Management and fruit thinning in commercial organic apple production systems in New York. Organic Farming Research Foundation. Funded projects. Managing insect pests. 23 June 2008. $<$ http://ofrf.org/funded/reports/robinson_01f14.pdf>

Sanchez, J.E., C.E. Edson, G.W. Bird, M.E. Whalon, R.R. Harwood, K. Kizilkaya, J.E. Nugent, W. Klein, A. Middleton, T.L. Loudon, D.R. Mutch, and J. Scrimger. 2003. Orchard floor and nitrogen management influences soil and water quality and tart cherry yields. J. Amer. Soc. Hort. Sci. 128:277-284.

Schmid, A. and F. Weibel. 2000. Das SandwichSystem -ein Verfahren zur herbizidfreien Baumstreifenbe- wirtschaftung? [The Sandwich System, a procedure for herbicide free in-row weed control?] Obstbau 25:214-217.

Stefanelli, D. 2006. Evaluation of orchard floor management systems for apple under organic protocol: Effect on soil organic matter and nitrogen, nematode community, root architecture and development, and rootstock performance. PhD Diss., Mich. State Univ., Dept. of Horticulture. Leaves 143-150.

Stork, P.R. and P.H. Jerie. 2003. Initial studies of the growth, nitrogen sequestering, and dewatering potential of perennial grass selections for use as nitrogen catch crops in orchards. Aust. J. Agr. Res. 54:27-37.

Webster, T. 2000. Apple and pear scion varieties and rootstocks for organic tree fruit production. Proc. Conf. 'Organic fruit-Opportunities \& challenges', Ashford, UK, 16-17 Oct. 2000.

Weibel, F. 2002. Soil management and in-row weed control in organic apple production. The Compact Fruit Tree 35:118-121.

Weibel, F. and A. Häseli. 2003. Organic apple production-With emphasis on European systems. In: Ferree, D.C. and I.J. Warrington (eds.). The CABI apple book. CABI Publishing, Wallingford, Oxon, UK.

Welker, W.V. and D.M. Glenn. 1991. Growth response of young peach trees to distribution pattern of vegetation-free area. HortScience 26:1141-1142.

Westwood, M.N. and A.N. Roberts. 1970. The relationship between trunk-cross sectional area and weight of apple trees. J. Amer. Soc. Hort. Sci. 95:28-30.

Yao, S., I.A. Merwin, G.W. Bird, G.S. Abawi, and J.E. Thies. 2005. Orchard floor management practices that maintain vegetative or biomass groundcover stimulate soil microbial activity and alter soil microbial community composition. Plant Soil 271:377-389.

Yussefi, M. 2004. Development and state of organic agriculture worldwide. The world of organic agriculture. Statistics and emerging trends 2004. IFOAM. In: Willer, H. and M. Yussefi (eds.). Verlagsservice Wilfried Niederland, Koeningstein, Germany. p. 167.

Zoppolo, R.J. 2004. Orchard floor management systems and rootstock performance of organically managed apples (Malus xdomestica Borkh.). PhD Diss., Michigan State University, Dept. of Horticulture. 